\title{
Heart donation after circulatory determination of death: ethically acceptable?
}

Anne L. Dalle Ave, David M. Shaw, Manuel Pascual and Lazare Benaroyo

We read the Review by Longnus et al. (Heart transplantation with donation after circulatory determination of death. Nat. Rev. Cardiol. 11, 354-363; 2014) ${ }^{1}$ with great interest. As stated by the authors, "heart transplantation with donation after circulatory determination of death (DCDD) is a promising strategy to reduce the shortage of donor hearts". However, only a few cases of heart DCDD have been reported in the literature, ${ }^{2,3}$ probably because of technical difficulties and unresolved ethical considerations. ${ }^{4}$ The Review by Longnus and colleagues relaunched the ethical debate on the possibility of heart DCDD. In this Correspondence, our objective is to discuss and analyse some of the ethical concerns raised by heart DCDD, which are briefly discussed by Longnus and colleagues, and to propose conditions under which this strategy would be ethically acceptable.

On the basis of a standard definition of cardiac death (the irreversible cessation of cardiovascular and respiratory functions), our analysis suggests that heart DCDD might not respect the 'dead donor rule', which states that vital organs should be transplanted only from dead patients. Indeed, the fact that heart function is restored in the recipient cancels the declaration of the donor's death, because cardiac cessation was, in fact, reversible. ${ }^{5}$ Two potential changes could be made to respect the dead donor rule. First, the definition of death could be based on the irreversible cessation of circulatory functions, and terms such as 'donation after cardiac death' should be abondoned. ${ }^{6}$ If this definition is adopted, the use of circulatory support (such as extracorporeal membrane oxygenation or a heart-lung machine) after the declaration of death should, in principle, be prohibited, because circulation would effectively be restored. However, the heart is sensitive to warm ischaemia time, which should probably not exceed 15-20 min to protect graft function. ${ }^{2,3,7}$ If heart DCDD is possible, it remains challenging, particularly if circulatory support is not used. Second, the definition of death could be based on brain-death criteria, ${ }^{8}$ but this approach has to be further analysed and discussed. Indeed, how long a state of irreversible brain death takes to reach is uncertain. Depending on the duration of this period, the heart might no longer be suitable for transplantation. How brain death would be tested in the context of heart DCDD remains uncertain and is a topic of research. Nevertheless, if the definition of brain death is adopted, restoration of cerebral circulation should be prohibited to allow the normal process of brain death. ${ }^{9}$

If heart DCDD is performed using a standard definition of cardiac death, disregarding the dead donor rule has been proposed. ${ }^{10,11}$ In our view, any such change would require society to acknowledge that abandoning the rule is acceptable because of a shortage of donor hearts and, therefore, to adopt a new norm. This change would be ethically questionable,$^{12}$ and would require public debate. ${ }^{13}$ After public communication of clear and transparent information about the ethical concerns, informed consent must have been previously given, for example by signing a donor card, for an individual to be considered for DCDD. Gaining consent from family members when an individual's donation intention is unknown raises difficult ethical problems, because families would need to be told that organs are to be taken 'before death'.

The Review by Longnus et al. ${ }^{1}$ on the feasibility of heart transplantation with DCDD is an important step forward, but the topic raises considerable ethical concerns, as acknowledged by the authors. Our view is that if we do not want heart DCDD to lead to public mistrust-which could extend to all DCDD organ programmes and possibly to the field of transplantation in generalan ethical debate among professionals is urgently required, before implementation of heart DCDD is pursued in clinical practice.

Ethics Unit (A.L.D.A., L.B.) and Transplantation Center (M.P.), University Hospital of Lausanne, Rue du Bugnon 46, Lausanne 1011, Switzerland. Institute for Biomedical Ethics, Bernoullistrasse 28, Basel 4056, Switzerland (D.M.S.).

Correspondence to: A.L.D.A.

anne.dalle-ave@chuv.ch

\section{Competing interests}

The authors declare no competing interests.

1. Longnus, S. L. et al. Heart transplantation with donation after circulatory determination of death. Nat. Rev. Cardiol. 11, 354-363 (2014).

2. Boucek, M. M., Mashburn C. et al. Pediatric heart transplantation after declaration of cardiocirculatory death. N. Engl. J. Med. 359, 709-714 (2008).

3. Ali, A. et al. Cardiac recovery in a human non-heart-beating donor after extracorporeal perfusion: source for human heart donation? J. Heart Lung Transplant. 28, 290-293 (2008).

4. Curfman, G. D., Morrissey, S. \& Drazen, J. M. Cardiac transplantation in infants. N. Engl. J. Med. 359, 749-750 (2008).

5. Veatch, R. M. Donating hearts after cardiac death-reversing the irreversible. N. Engl. J. Med. 359, 672-673 (2008).

6. Bernat, J. The boundaries of organ donation after circulatory death. N. Engl. J. Med. 359, 669-671 (2008).

7. Southerland, K. W. et al. Impact of donor cardiac arrest on heart transplantation. Surgery 154, 312-319 (2013).

8. Veatch, R. M. Transplanting hearts after death measured by cardiac criteria: the challenge to the dead donor rule. J. Med. Phil. 35, 313-329 (2010).

9. Bernat, J. L. et al. The circulatory-respiratory determination of death in organ donation. Crit. Care Med. 38, 963-970 (2010).

10. Truog, R. D. \& Miller, F. G. The dead donor rule and organ transplantation. N. Engl. J. Med. 359, 674-675 (2008).

11. Miller, F. G. Heart donation without the dead donor rule. Ann. Thor. Surg. 97, 1133-1134 (2014).

12. Bernat, J. L. Life or death for the dead-donor rule? N. Engl. J. Med. 369, 1289-1291 (2013).

13. Kirby, J. Ethically informed pragmatic conditions for organ donation after cardiocirculatory death: could they assist in policy development? J. Clin. Ethics 24, 373-380 (2014). 